\title{
Professionals' barriers in female oncofertility care and strategies for improvement
}

\author{
M. van den Berg',*, Ö. Baysal', W.L.D.M. Nelen', D.D.M. Braat', \\ C.C.M. Beerendonk', and R.P.M.G. Hermens ${ }^{2}$
}

'Department of Obstetrics and Gynaecology, Radboud university medical center, PO Box 9101 , 6500HB Nijmegen, the Netherlands
2Department of IQ Healthcare, Radboud university medical center, PO Box 910I, 6500HB Nijmegen, the Netherlands

*Corresponding address. Department of Obstetrics and Gynaecology, Radboud university medical center, P.O. Box 910I, 6500HB Nijmegen, the Netherlands. Tel: +3I(0)2436I4727; Fax: +3I(0)24 36 I 47 26; E-mail: Michelle.vandenBerg@radboudumc.nl

Submitted on October 22, 2018; resubmitted on April 12, 2019; editorial decision on April 15, 2019

STUDY QUESTION: What are healthcare professionals' barriers and strategies for improvement in female oncofertility care? SUMMARY ANSWER: Professionals perceived barriers in knowledge, attitude and organization of oncofertility care and suggested strategies to improve oncofertility care.

WHAT IS KNOWN ALREADY: The potential loss of fertility is one of the most important undesirable side effects of cancer treatment in women of reproductive age. Unfortunately, despite guideline recommendations, not all patients are informed about their fertility risks and referred for fertility preservation (FP) counselling. Insight into barriers for discussing FP and appropriate referral is necessary before improvements can be made.

STUDY DESIGN, SIZE, DURATION: The aim of this was study was to identify barriers and gather improvement suggestions through semi-structured in-depth interviews conducted with 24 professionals working in oncofertility care. Subsequently, an expert panel meeting was held to reach consensus on a set of improvement strategies.

PARTICIPANTS/MATERIALS, SETTING, METHODS: Oncological professionals were recruited from the three Dutch expertise hospitals for female FP and their affiliated hospitals. The expert panel consisted of six healthcare professionals, five survivors and two researchers. In the Dutch setting, financial aspects do not play a role in oncofertility care.

MAIN RESULTS AND THE ROLE OF CHANCE: Barriers were identified and categorized into the patient level (e.g. focus on surviving cancer), the professional level (e.g. lack of awareness, knowledge, time, and attitude), or the organizational level (e.g. unavailable written information, disagreement on who is responsible for discussing infertility risks). The expert panel reached consensus on essential elements for a multifaceted improvement programme: development of information materials (leaflets, online decision aid), education of professionals, a role for specialized oncology nurses in informing patients and patient navigators at the fertility department to facilitate referral and counselling, medical record reminders, standard consultations with a gynaecologist and agreement on responsibility.

LIMITATIONS, REASONS FOR CAUTION: Selection bias could have occurred because it is likely that only professionals with interest in oncofertility care participated. However, this would mean that the barriers were underestimated.

WIDER IMPLICATIONS OF THE FINDINGS: This study forms the basis for the development of a multifaceted oncofertility programme, which is essential to increase adherence to the national clinical guideline.

STUDY FUNDING/COMPETING INTEREST(S): This work was supported by the Radboud university medical center. The authors have declared no competing interests. Prof. Dr Braat reports unrestricted grants from Ferring BV, Serono and Goodlife, outside the submitted work. TRIAL REGISTRATION NUMBER: N/A

Key words: oncofertility / fertility preservation / female / cancer / barriers / improvement

(C) The Author(s) 2019. Published by Oxford University Press on behalf of the European Society of Human Reproduction and Embryology.

This is an Open Access article distributed under the terms of the Creative Commons Attribution Non-Commercial License (http://creativecommons.org/licenses/by-nc/4.0/), which permits non-commercial re-use, distribution, and reproduction in any medium, provided the original work is properly cited. For commercial re-use, please contact journals.permissions@oup.com 


\section{Introduction}

Over the past decades, the rates of cancer survivorship in young female patients have increased (De Angelis et al. 20I4). Therefore, attention should be paid to the late side effects of cancer treatment and longterm quality of life issues (DCOG 20I0). One of the most important undesirable side effects of cancer treatment in women of reproductive age is the potential loss of fertility. Some women even report the potential loss of fertility almost as distressing as the battle with cancer itself (Tschudin and Bitzer 2009). When damage to reproductive organs is likely, oophoropexy or cryopreservation of embryos or oocytes are effective options available for women to preserve fertility prior to starting their cancer treatment; cryopreservation of ovarian tissue is still considered as experimental (Donnez and Dolmans 2017).

The optimal oncofertility care for young female cancer patients is described in several evidence-based national and international clinical practice guidelines (ASRM 20I3a; NICE 20I3; NVOG 2016; Oktay et al. 2018). These guidelines recommend discussing the potential loss of fertility with all female cancer patients and, if desired, offering a referral to and counselling by a fertility specialist. Hereafter, a patient can decide whether she wants to undergo fertility preservation (FP) treatment. Information about fertility issues related to cancer treatment should be provided, irrespective of a female cancer patient's reproductive age, parity, and disease type or severity (Oktay et al. 20I8). Providing information, referral, and counselling to these patients affects quality of life positively, reduces long-term regret, and reduces concerns regarding fertility (Benedict et al. 2016; Deshpande et al. 2015; Letourneau et al. 2012; Oktay et al. 2018).

Unfortunately, studies have shown that despite these evidencebased recommendations, the rates of patients who received information about their fertility risks and FP options still vary greatly, from 51\% to 95\% (Adams et al. 2013; Forman et al. 20 I0; Letourneau et al. 2012; Louwe et al. 20I8; Niemasik et al. 20I2). The referral process to a fertility specialist also shows variation in practice, with $9.8-67 \%$ of these patients being referred (Adams et al. 2013; Bastings et al. 20 14; Quinn et al. 2009). It is important to get insight into barriers for delivering optimal oncofertility care to reduce this variation in practice and improve oncofertility care and guideline adherence.

Reported barriers in international literature impeding oncologists from discussing infertility risks and FP options are as follows: a lack of time, knowledge, or resources; a need for immediate cancer therapy; perceived poor success rates of FP options; poor patient prognosis; and patient characteristics (e.g. higher age and parity) (Adams et al. 20 I3; Besharati et al. 20 I6; Jones et al. 20 I7; Peddie et al. 20 I2; Quinn et al. 2007; Quinn et al. 2009). However, most of these studies have been performed in countries where financial aspects also play a key role in professionals' decisions to inform and refer a patient for FP counselling (Adams et al. 2013; Goodman et al. 2012; Rashedi et al. 2018). In the Netherlands, cancer care and FP options are reimbursed by standard health care insurance. The first aim of our study was therefore to assess barriers and improvement suggestions among healthcare professionals in female oncofertility care in a setting where financial aspects do not play a role. Furthermore, whereas multiple studies have assessed barriers in providing optimal oncofertility care, none have included tailoring improvement strategies. Therefore, the second aim of our study was to identify essential elements for a tailored programme to overcome barriers and improve oncofertility care.

\section{Materials and Methods}

\section{Design}

Our study consisted of two parts. First, semi-structured in-depth interviews were conducted with healthcare professionals to identify their barriers and improvement suggestions in female oncofertility care. Second, tailored improvement strategies were selected with patient and healthcare professional experts to overcome the barriers, fitting it into a nationwide oncofertility programme.

\section{Setting}

In the Netherlands, cancer patients receive multidisciplinary oncological care and can be referred for specialized FP care by any medical specialist involved. Dutch breast cancer patients also need referral to a gynaecologist for FP counselling, because they are operated on by surgical oncologists. At three Dutch hospitals, all FP options, including ovarian tissue cryopreservation, are performed (expertise hospitals: Radboudumc Nijmegen, LUMC Leiden, and Erasmus MC Rotterdam).

All legal residents of the Netherlands are obliged by law to have basic health insurance, which covers FP counselling and all FP options, meaning that patients have no financial reasons to refrain from it.

\section{Study population}

\section{Part I: Identification of barriers and improvement suggestions}

Professionals involved in Dutch female oncofertility care were eligible to participate in the study. They included medical, gynaecological and surgical oncologists, haematologists, specialized oncology nurses, and reproductive gynaecologists. They were recruited from the three Dutch expertise hospitals for female FP care (Radboudumc, LUMC, and ErasmusMC) and their approximately 20 affiliated hospitals. Professionals $(N=43)$ were approached by the researcher $(M B)$ by email to participate. Depending on the professional's preference, interviews were conducted in person or via telephone. They were not offered compensation for their participation.

\section{Part II: Selection of improvement strategies}

Both patients and professionals were eligible to participate in the expert panel meeting. Patients were recruited from the following patients' networks: Olijf (gynaecological cancers), AYA (national adolescent and young adult) platform, and the patient advisory board of the research theme Women's Cancers at the Radboudumc. Professionals were recruited from the Radboudumc and its affiliated hospitals. In total, 22 experts were invited to participate.

\section{Data collection and analysis}

Part I: Identification of barriers and improvement suggestions

Semi-structured, in-depth interviews were performed to identify professionals' barriers and improvement suggestions. Interviews were preferred over a survey because we wanted to obtain in-depth and detailed information on barriers and improvement suggestions.

The interview guide was based on key recommendations for highquality female oncofertility care, previously identified by our research team (ÖB, MB, DB, WN, RH, CB). These key recommendations were extracted and selected by a multidisciplinary expert panel from six 
national and international guidelines, then appraised as high-quality guidelines by our research team, complemented with the Dutch guideline using a Delphi consensus procedure (Baysal et al. 2018). The key recommendations are distributed over the FP healthcare pathway for patients (risk communication, referral, counselling, and decisionmaking) and shown in Supplementary Table I. Barriers and improvement suggestions regarding risk communication and referral were discussed in the interviews, while barriers regarding counselling and decision-making have been identified previously (Bastings et al. 20I4).

Different levels, based on the framework developed by Flottorp et al. 2013, were used to explore barriers and improvement suggestions. This framework facilitates identification and assessment of potential barriers using seven levels: guideline-related factors, patients, professionals, professional interactions, incentives and resources, organization, and social, legal and political characteristics. The interview guide was adapted when new barriers or improvement suggestions were identified, and is provided in the Supplementary Information. All interviews were conducted by M.B. in 2016, and the number of interviews was determined by data saturation (the point at which no new information was mentioned). To confirm that no new information was mentioned, three additional interviews were conducted.

In order to analyse data, all interviews were recorded and transcribed verbatim. Transcripts were not returned to participants for comments. The texts were imported in qualitative research software Atlas.ti (version 7.I.5,Berlin) and coding was, again, guided by Flottorp's framework (Flottorp et al. 20I3). The coding process consisted of four steps. All steps were performed independently by two researchers (MB and $\mathrm{OB}$ ) to increase reliability and validity. First, all interview transcripts were read. Second, both researchers selected and labelled phrases in which potential barriers or improvement suggestions were described using open encoding. These codes were then grouped into categories and finally, these categories were assigned to the appropriate levels, as described by Flottorp. After each step, the results were compared, and any discrepancies were discussed until consensus was reached. If no consensus was reached, a third independent person (WN) was consulted. The inter-coder score was calculated by percent agreement, because it is unlikely that agreement would occur by chance (Lombard 2002). The two coders agreed on 717 out of the initial 778 codes (92\% agreement) and discussed about 61 out of 778 codes (8\% disagreement). All disagreements included codes that were initially missed and not coded by either one of the researchers. The inter-coder score of $92 \%$ is deemed acceptable (Lombard 2002).

\section{Part II: Selection of improvement strategies}

In the second part of our study, an expert panel meeting was held in 2018 to select improvement strategies to overcome the identified barriers. Again, the framework of Flottorp was used (Flottorp et al. 2013). To select strategies, a prioritization of barriers was necessary, because barriers that have a large influence on the performance objective are likely to be important targets for an intervention.

The expert panel meeting was led by the main researcher (MB) and started with the presentation of all barriers identified in the interviews, complemented with the barriers identified in previous research (Bastings et al. 20I4). All barriers are presented in Table II. Thereafter, the expert panel was divided into three subgroups, each consisting of patients and professionals. Each subgroup separately discussed all barriers, added new barriers, and scored the impact of each barrier on a scale of one to three. The impact score represented to what extent the barrier hindered the adherence to the key recommendation (I: minor extent, 2: moderate extent, 3: major extent) (Flottorp et al. 2013). Thus, for three subgroups, the minimum score was three and the maximum score was nine.

The scores of all subgroups were added together for each barrier, and a priority list was made. The top eight identified barriers were considered most important because of the feasibility of implementing adherent improvement strategies for a total of eight barriers in a multifaceted improvement strategy (Grimshaw et al. 20I2; Kersten et al. 2017). These eight barriers and their associated improvement strategies were discussed with the entire expert panel as part of the development of a multifaceted programme, taking into account the improvement suggestions identified in part I. Finally, the selection of improvement strategies was based on the suggestions made by the professionals in the in-depth interviews, on the priority given by the expert panel and on previous research (Flottorp et al. 2013; Kok et al. 2016). Thus, both exploratory and theory-inspired methods were used to select interventions as is recommended in the review by Wensing et al. 2010.

\section{Ethical approval}

Approval for this study by an ethics committee was not required, in line with Dutch guidelines. The study was performed in accordance with the Declaration of Helsinki, and written consent was obtained from all participants.

\section{Results}

\section{Part I: Identification of barriers and improvement suggestions}

In total, 24 out of 43 individual professionals agreed to participate in the interviews. Reasons for declining participation were a lack of time $(N=4)$, not experiencing problems in FP discussions $(N=2)$, and not responding to the initial or follow-up invitations $(\mathrm{N}=13)$. The participants' characteristics are presented in Table I.

A total of 28 barriers and 18 improvement suggestions were identified in the interviews, categorized into the patient, professional, and care organization level. Table II shows all barriers and Table III shows all improvement suggestions. Both are ranked by the number of times they were mentioned (range, I-23). Barriers and improvement suggestions mentioned most by the professionals are described in the text below. To provide a degree of quantification, we have used words to define rates of mentions: almost all, most, some, half and a third. Supplementary Table II shows illustrative quotes of some suggested barriers.

\section{Patient level}

\section{Barriers}

Most oncological professionals reported that they feel that patients do not place fertility high on their priority list because they are focused on surviving cancer. Furthermore, according to some professionals, patients are not motivated to preserve their fertility because they want to start their cancer treatment as soon as possible. 
Table I Participants' characteristics.

\begin{tabular}{|c|c|c|}
\hline Part of study & Characteristics & Value, $\mathbf{N}(\%)$ \\
\hline \multirow[t]{25}{*}{ Part I } & Type of professional $(N=24)$ & \\
\hline & Medical oncologist & 7 (29\%) \\
\hline & Surgical oncologist & 7 (29\%) \\
\hline & Gynaecological oncologist & $2(8 \%)$ \\
\hline & Haematologist & I (4\%) \\
\hline & Specialized oncology nurse & I (4\%) \\
\hline & Specialized breast cancer nurse & $4(17 \%)$ \\
\hline & Reproductive gynaecologist & $2(8 \%)$ \\
\hline & Gender & \\
\hline & Male & $3(12 \%)$ \\
\hline & Female & $21(88 \%)$ \\
\hline & Type of hospital & \\
\hline & Academic hospital & $15(63 \%)$ \\
\hline & Non-academic hospital & $9(37 \%)$ \\
\hline & Years of experience & \\
\hline & $0-5$ years & $3(12 \%)$ \\
\hline & $5-9$ years & II (46\%) \\
\hline & $10-19$ years & $5(2 \mid \%)$ \\
\hline & 20-29 years & $5(2 \mid \%)$ \\
\hline & Number of oncofertility patie & \\
\hline & $\leq 10$ patients & $2(8 \%)$ \\
\hline & II-20 patients & $10(42 \%)$ \\
\hline & $21-30$ patients & $5(2 \mid \%)$ \\
\hline & $>30$ patients & $6(25 \%)$ \\
\hline & Unknown & I (4\%) \\
\hline \multirow[t]{14}{*}{ Part II } & Type of experts $(N=13)$ & \\
\hline & Researchers, quality of care & $2(15 \%)$ \\
\hline & Professionals & $6(46 \%)$ \\
\hline & Medical oncologist & 2 \\
\hline & Gynaecological oncologist & 1 \\
\hline & Specialized oncology nurse & 1 \\
\hline & Specialized fertility nurse & 2 \\
\hline & Survivors & 5 (39\%) \\
\hline & Breast cancer & 2 \\
\hline & Gynaecological cancer & 2 \\
\hline & Soft tissue sarcoma & 1 \\
\hline & Gender & \\
\hline & Male & I (8\%) \\
\hline & Female & 12 (92\%) \\
\hline
\end{tabular}

Part I: Barrier and improvement suggestion identification. Part II: Selection of improvement strategies.

\section{Improvement suggestions}

Almost all professionals think an online individualized decision-aid on oncofertility and handing out information leaflets at the oncology department will improve oncofertility care. Furthermore, they think that it would help if patients themselves were aware of infertility risks when they receive gonadotoxic cancer treatments. Awareness could be created, for example, by a national campaign by the cancer society, or through more online information by disease-specific cancer associations.

\section{Professional level}

\section{Barriers}

Most professionals reported that they routinely discuss FP, but lack the knowledge of the FP options, methods, and tools, particularly 
Table II Professionals' barriers in female oncofertility care.

\begin{tabular}{|c|c|c|}
\hline Phase of FP & Level & Barrier \\
\hline \multirow{17}{*}{$\begin{array}{l}\text { Risk } \\
\text { communication } \\
\text { and referral }\end{array}$} & \multirow[t]{4}{*}{ Patient } & Fertility is not a priority for patients; they focus on surviving cancer* \\
\hline & & Patients are not motivated; they focus on immediate cancer treatment \\
\hline & & Patients are scared of IVF \\
\hline & & Patients do not come up with the fertility topic themselves \\
\hline & \multirow[t]{8}{*}{ Professional } & $\begin{array}{l}\text { Professionals lack knowledge } \\
\text { - of FP options* } \\
\text { - of infertility risks } \\
\text { - regarding FP options in different cancer types }\end{array}$ \\
\hline & & Particularly professionals working in non-academic hospitals lack knowledge of FP \\
\hline & & $\begin{array}{l}\text { Professionals lack awareness } \\
\text { - of the decision aid* } \\
\text { - of the FP guideline } \\
\text { - in patients with an older age* } \\
\text { - in patients with a higher parity } \\
\text { - in patients with a poor prognosis } \\
\text { - in patients without a (active) wish to conceive } \\
\text { - in mentally disabled patients } \\
\text { - in single patients }\end{array}$ \\
\hline & & Particularly surgical oncologists lack awareness of FP \\
\hline & & $\begin{array}{l}\text { Professionals have a lack of time* } \\
\text { - professionals have to provide too much information at diagnosis } \\
\text { - professionals do not provide written information }\end{array}$ \\
\hline & & $\begin{array}{l}\text { Professionals have a lack of agreement } \\
\text { - surgical oncologists believe that medical oncologists are responsible for FP discussions } \\
\text { - if there is no definitive treatment plan }\end{array}$ \\
\hline & & $\begin{array}{l}\text { Professionals have a lack of self-efficacy } \\
\quad-\text { FP is a difficult topic for them to discuss }\end{array}$ \\
\hline & & $\begin{array}{l}\text { Professionals have a lack of outcome expectancy } \\
\text { - professionals think they scare women when they discuss FP }\end{array}$ \\
\hline & \multirow[t]{5}{*}{ Organization } & Written information is not available* \\
\hline & & FP is not discussed at multidisciplinary meetings \\
\hline & & It is difficult to arrange an appointment with a gynaecologist for a patient \\
\hline & & Disagreement between departments on who is responsible for fertility discussions \\
\hline & & No nurses are available to support professionals \\
\hline \multirow{6}{*}{$\begin{array}{l}\text { Counselling and } \\
\text { decision-making }\end{array}$} & \multirow[t]{2}{*}{ Patient } & Patients do not feel supported \\
\hline & & Patients' preferences are not taken into account by gynaecologists \\
\hline & \multirow[t]{2}{*}{ Professional } & $\begin{array}{l}\text { Professionals have a lack of communication } \\
\text { - patients do not have the opportunity to ask all questions }\end{array}$ \\
\hline & & $\begin{array}{l}\text { Professionals provide incomplete information } \\
\text { - not all applicable options are discussed } \\
\text { - not all benefits and disadvantages of FP options are clearly explained }\end{array}$ \\
\hline & \multirow[t]{2}{*}{ Organization } & Written information is not available \\
\hline & & Professionals lack time for counselling \\
\hline
\end{tabular}

FP, fertility preservation; IVF, in vitro fertilization.

* More than $50 \%$ of all professionals mentioned the barrier.

the options corresponding to different cancer types. In addition, most professionals reported being less aware of discussing fertility in patients who are of a higher age, who have children, who don't have a (clear) wish to conceive or who have a poor cancer prognosis.

Furthermore, half of the professionals reported lacking the time to discuss fertility, because they have to give a large amount of information regarding the cancer diagnosis in the first consultation with a new patient. Regarding professionals' attitude towards FP, the most frequent mentioned barrier was disagreement between surgical oncologists and medical oncologists on who is responsible for discussing infertility risks.

\section{Improvement suggestions}

Improving professionals' awareness of FP is an important suggestion. Most professionals think this could be achieved through education by 
Table III Professionals' improvement suggestions in female oncofertility care.

\begin{tabular}{|c|c|c|}
\hline Phase of FP & Level & Improvement suggestion \\
\hline \multirow[t]{14}{*}{$\begin{array}{l}\text { Risk communication and } \\
\text { referral }\end{array}$} & Patient & $\begin{array}{l}\text { Development and provision of patient information materials } \\
\text { - Decision aid* } \\
\text { - Leaflets* } \\
\text { - Option grid }\end{array}$ \\
\hline & & Increase patients' awareness \\
\hline & & Professionals refer women for FPC who have doubts \\
\hline & Professional & $\begin{array}{l}\text { Education of professionals* } \\
\text { - Educate professionals' way of communication }\end{array}$ \\
\hline & & Increase professionals' awareness* \\
\hline & & Surgical oncologists refer women for FPC* \\
\hline & & Feedback to professionals on their performance \\
\hline & Organization & Role for specialized oncology nurses* \\
\hline & & Fertility is a standard item at multidisciplinary meetings* \\
\hline & & Easy referral process* \\
\hline & & $\begin{array}{l}\text { Standard consultations with a gynaecologist for all female cancer patients of } \\
\text { reproductive age* }\end{array}$ \\
\hline & & Reminders in medical record \\
\hline & & $\begin{array}{l}\text { Agreement between healthcare departments on who is responsible for fertility } \\
\text { discussions }\end{array}$ \\
\hline & & Fertility is mentioned in each cancer-specific protocol \\
\hline $\begin{array}{l}\text { Counselling and } \\
\text { decision-making }\end{array}$ & Organization & Implementation of a patient navigator at the fertility department \\
\hline
\end{tabular}

FPC, fertility preservation counselling.

* More than $50 \%$ of all professionals mentioned the improvement suggestion.

gynaecologists with expertise in FP. Furthermore, most professionals reported that surgeons should refer breast cancer patients to a gynaecologist for FP counselling in order to leave more time for FP before cancer treatment. Another suggested improvement is to create awareness among oncological professionals on positive or negative ways of communication about infertility risks and FP options.

\section{Organization level}

\section{Barriers}

At the level of the organization, the barrier most frequently mentioned was the lack of available written FP information at their department. Furthermore, at a third of the hospitals, fertility issues are not routinely discussed at the weekly multidisciplinary team meetings (i.e. meetings where treatment plans for all newly diagnosed cancer patients are discussed).

\section{Improvement suggestions}

Almost all professionals mentioned that specialized oncology nurses should have a role in FP care, because nurses have more interest in the psychosocial aspect of the cancer diagnosis. It may, therefore, be logical to give them a role in the FP discussion. Furthermore, almost all professionals reported that fertility should be discussed at those weekly multidisciplinary team meetings, including appointing a primarily responsible physician at each hospital.

\section{Part II: Selection of improvement strategies}

In total, 13 out of 22 experts agreed to participate in the expert panel meeting. The reason for declining participation was a lack of time. Participants' characteristics are shown in Table I.

Patients in the expert panel agreed with the identified barriers among professionals. Two additional barriers were identified by the patients in the expert panel: namely, that prior to the cancer treatment only the medical perspective is discussed at multidisciplinary team meetings, without a mention of consequences for fertility and that no attention is paid to reproductive concerns after cancer treatment. Based on the scores of all subgroups for each barrier, a priority list was made. Table IV shows the top eight barriers distributed over the FP healthcare pathway for patients, and the seven selected improvement strategies on which consensus was reached to overcome these barriers.

\section{Discussion}

This study reports the findings of a qualitative, in-depth assessment of perceived barriers and improvement suggestions among professionals working in oncofertility care. Barriers have been revealed by using the model of Flottorp and have been categorized into patient, professional, and organizational levels. On the patient level, a focus on surviving cancer instead of fertility, on the professional level, a lack of awareness and a lack of knowledge, and on the organizational level, a lack of available written information and disagreement on who is responsible 
Table IV Barriers and their impact score including the selected improvement strategies.

\begin{tabular}{|c|c|c|c|}
\hline Phase of FP & Impact score & Barrier & $\begin{array}{l}\text { Adherent improvement } \\
\text { strategies }\end{array}$ \\
\hline Risk communication & 9 & Lack of knowledge & I \\
\hline \multirow[t]{5}{*}{ Referral } & 9 & Lack of awareness & I, 2, 3 \\
\hline & 9 & $\begin{array}{l}\text { Disagreement between departments on who is responsible for fertility } \\
\text { discussions }\end{array}$ & 4 \\
\hline & 8 & No written information available & 5 \\
\hline & 8 & Fertility is not a priority for cancer patients & $3,5,6$ \\
\hline & 7 & Lack of time & 6 \\
\hline Counselling & 7 & Incomplete information in FP counselling & 5,7 \\
\hline \multirow[t]{2}{*}{ Decision-making } & 7 & Gynaecologist does not take patients' preferences into account & 7 \\
\hline & & No attention for reproductive concerns after cancer treatment* & 6,7 \\
\hline
\end{tabular}

for discussing fertility, were mentioned as main barriers for optimal oncofertility care. During the expert panel meeting, in which patients also took part, these barriers were confirmed and the barrier that no attention is paid to reproductive concerns after cancer treatment was added. The improvement strategies selected by the expert panel were as follows: development and availability of patient information materials (leaflets, decision aid), education of professionals, a role for specialized oncology nurses in discussing fertility issues, reminders in the medical record, standard consultations with a gynaecologist, agreement in each hospital on who is responsible to discuss infertility risks, and a role for patient navigators at the fertility department.

To the best of our knowledge, this is the first study to identify barriers and tailor improvement strategies to these barriers to deliver optimal oncofertility care. Previous studies have examined barriers or improvements separately, but not concurrently. The identified barriers were in line with earlier studies, in which a lack of professionals' knowledge and patients' characteristics (higher age, higher parity, and poor cancer prognosis) were also identified as barriers (Adams et al. 2013; Jones et al. 2017; Quinn et al. 2007; Quinn et al. 2009). It is striking that despite the presence of national clinical guidelines and a national website on FP (www.nnf-info.nl), the main barriers among professionals were still a lack of awareness and a lack of knowledge. A possible explanation is that professionals are unaware of these guidelines, because they are published in journals and websites that are mainly read by gynaecologists and not by professionals working in oncology care. Therefore, in an attempt to overcome this barrier, the most recent national FP guideline is also published on the Dutch national oncology website and on the national guideline database (NVOG 2016).

Another identified barrier was that professionals feel that women focus on surviving cancer and not on their risk of infertility. Earlier studies have also identified this, the need for immediate therapy either by the professional or by the patient (Jones et al. 2017; Niemasik et al. 2012; Quinn et al. 2007). However, other studies reported that cancer survivors have more decisional conflict and regret, and a lower quality of life if they had not received specialized FP counselling (Letourneau et al. 2012; Mersereau et al. 2013). An implication of this finding is that professionals should correctly prioritize the fertility topic at the appropriate moment. Therefore, education of professionals is needed, in particular on oncofertility knowledge and communication skills. Moreover, specialized oncology nurses can play an important role in this. The effectiveness of nurses participating in oncofertility care has already been studied; nurses feel responsible for addressing fertility issues, patients are more satisfied, and more referrals for FP counselling take place (Cohen et al. 2016; Krouwel et al. 2017; Srikanthan et al. 2016).

One of the strengths of our study is the recruitment of a great diversity of professionals from the three Dutch expertise academic hospitals for female FP care and their affiliated non-academic hospitals. This provides a reflection of the perceived barriers and improvement suggestions throughout the Netherlands. Another strength is the indepth insight into the barriers and improvement suggestions, in contrary to previous studies where only a quantitative assessment was performed. This provided us with more detailed information and more input to select improvement strategies.

This study also has some limitations. First, all professionals were asked for participation via email. It is likely that only professionals with interest in oncofertility care participated in this study. However, this would mean that we have underestimated the number of barriers and that even more barriers exist. To identify non-participants' barriers, we could have sent an online survey. However, 13 out of the 19 participants who declined participation did not respond to our email invitations at all, so they would be very unlikely to respond to a survey. Furthermore, the question is whether it would have revealed additional barriers, because most barriers in our study were identified by exploring them in-depth. Second, patients were involved in the expert panel meeting, but not in the barrier identification. Results might have been different if individual interviews were performed with both professionals and patients. To reduce these possible differences, all patients received an overview of the identified barriers 2 weeks 
prior to the expert panel meeting, in order to have enough time to agree with the identified barriers and/or to add new barriers. Third, bias could have occurred in the interpretation of the interview transcripts. Therefore, all interview transcripts were independently coded by two researchers, and discrepancies were discussed. Fourth, most interviewed professionals worked at an academic hospital at which FP awareness might be higher due to short communication lines between oncology and fertility departments. However, this would also signify an underestimation of the barriers.

The establishment and dissemination of the national clinical female oncofertility care guideline is not sufficient to improve care. In order to improve adherence to the guideline, implementation activities are necessary. Our tailored improvement strategies form the basis for a multifaceted oncofertility programme, which is an important and essential implementation activity. In Canada and the United States of America, dedicated cancer and fertility programmes were developed and evaluated for their effect on patient satisfaction, information provision, and referral. These studies have shown improvements in patient satisfaction and more referrals (Cohen et al. 2016; Kelvin et al. 2016; Srikanthan et al. 2016). These outcomes are promising for the design of a nationwide oncofertility programme in the Netherlands, since FP care is reimbursed in our country and patients and professionals have no financial reasons to refrain from referral for FP counselling.

\section{Conclusion}

In summary, this is the first study to identify barriers and tailor improvement strategies associated with these barriers, with the aim of delivering optimal oncofertility care. Professionals particularly perceived barriers in awareness, knowledge, attitude, and organization of female oncofertility care. To overcome these barriers, patients and professionals selected seven tailored improvement strategies, including development of patient information materials, education of professionals, roles for specialized oncology nurses, and agreement in each hospital on who is responsible for discussing infertility risks. This selection forms the basis for a multifaceted oncofertility programme, which is essential to increase adherence to the national clinical guideline on female oncofertility care to provide a better quality of life for female cancer survivors.

\section{Supplementary data}

Supplementary data are available at Human Reproduction online.

\section{Acknowledgements}

We would like to thank all healthcare professionals and patients (presented in Supplementary Table III in alphabetical order) for participating in either individual interviews or in the expert panel.

\section{Authors' roles}

M.B. and R.P.M.G.H. carried out the study. M.B., O.B., W.L.D.M.N., and R.P.M.G.H. interpreted and analysed data. M.B. wrote the original draft. All authors reviewed the article. All authors were involved in the conception and design of the study and gave final approval of the article.

\section{Funding}

Radboud university medical center.

\section{Conflict of interest}

All authors declare no competing interests. Prof. Dr Braat reports unrestricted grants from Ferring BV, Serono, and Goodlife, outside the submitted work.

\section{References}

Adams E, Hill E, Watson E. Fertility preservation in cancer survivors: a national survey of oncologists' current knowledge, practice and attitudes. Br J Cancer 2013; 108: 1602-1615.

ASRM. Practice Committee of American Society for Reproductive Medicine. Fertility preservation and reproduction in patients facing gonadotoxic therapies: a committee opinion. Fertil Steril 20 I3a; 100: |224-|23|.

Bastings L, Baysal Ö, Beerendonk CC, Braat DD, Nelen WL. Referral for fertility preservation counselling in female cancer patients. Hum Reprod 2014;29:2228-2237.

Bastings L, Baysal Ö, Beerendonk CC, IntHout J, Traas MA, Verhaak CM, Braat DD, Nelen WL. Deciding about fertility preservation after specialist counselling. Hum Reprod 2014;29: I721-1729.

Baysal Ö, Hamilton JA, Hamilton CJ, Braat DD, Beerendonk CC, Nelen WL. Clinical practice guidelines for fertility preservation in young women undergoing gonadotoxic treatment: an overview and critical appraisal of methodological quality and content. Reprod Biomed Online 2018;37:60-70.

Benedict C, Thom B, Friedman D, Diotallevi D, Pottenger E, Raghunathan N, Kelvin JF. Young adult female cancer survivors' unmet information needs and reproductive concerns contribute to decisional conflict regarding posttreatment fertility preservation. Cancer 2016; I 22:2101-2109.

Besharati M, Woodruff T, Victorson D. Young adults' access to fertility preservation services at national cancer institute community oncology research program minority/underserved community sites: a qualitative study. J Adolesc Young Adult Oncol 2016;5: 187-200.

Cohen L, Hamer J, Helwig C, Fergus K, Kiss A, Mandel R, Dawson B, Landsberg A, Shein K, Kay N et al. Formal evaluation of PYNK: breast cancer program for young women-the patient perspective. Curr Oncol 2016;23: 102-108.

DCOG (Dutch Childhood Oncology Group). Guidelines for Followup in Survivors of Childhood Cancer 5 Years After Diagnosis. 20I0. https://www.skion.nl/workspace/uploads/vertalingrichtlijn-LATER-versie-final-okt-20।4_2.pdf. 22 October 20।8, date last accessed.

De Angelis R, Sant M, Coleman MP, Francisci S, Baili P, Pierannunzio $D$, Trama A, Visser O, Brenner H, Ardanaz E et al. Cancer survival in Europe 1999-2007 by country and age: results of EUROCARE-5-a population-based study. Lancet Oncol 20 I4; I5:23-34.

Deshpande NA, Braun IM, Meyer FL. Impact of fertility preservation counseling and treatment on psychological outcomes among women with cancer: a systematic review. Cancer 20 I 5; I 2 I:3938-3947.

Donnez J, Dolmans MM. Fertility preservation in women. N Engl J Med 2017;377:1657-1665. 
Flottorp SA, Oxman AD, Krause J, Musila NR, Wensing M, GoyckiCwirko M, Baker R, Eccles MP. A checklist for identifying determinants of practice: a systematic review and synthesis of frameworks and taxonomies of factors that prevent or enable improvements in healthcare professional practice. Implement Sci 20 I3;8:35.

Forman EJ, Anders CK, Behera MA. A nationwide survey of oncologists regarding treatment-related infertility and fertility preservation in female cancer patients. Fertil Steril 2010;94:1652-1656.

Goodman LR, Balthazar U, Kim J, Mersereau JE. Trends of socioeconomic disparities in referral patterns for fertility preservation consultation. Hum Reprod 2012;27:2076-208I.

Grimshaw JM, Eccles MP, Lavis JN, Hill SJ, Squires JE. Knowledge translation of research findings. Implement Sci 20 I2; 7:50.

Jones G, Hughes J, Mahmoodi N, Smith E, Skull J, Ledger W. What factors hinder the decision-making process for women with cancer and contemplating fertility preservation treatment? Hum Reprod Update 2017;23:433-457.

Kelvin JF, Thom B, Benedict C, Carter J, Corcoran S, Dickler MN, Goodman KA, Margolies A, Matasar MJ, Noy A et al. Cancer and fertility program improves patient satisfaction with information received. J Clin Oncol 2016;34:1780-1786.

Kersten FAM, Nelen WL, van den Boogaard NM, van Rumste MM, Koks CA, IntHout J, Verhoeve HR, Pelinck MJ, Boks DES, Gianotten J et al. Implementing targeted expectant management in fertility care using prognostic modelling: a cluster randomized trial with a multifaceted strategy. Hum Reprod 2017;32:1648-1657.

Kok G, Gottlieb NH, Peters GJ, Mullen PD, Parcel GS, Ruiter RA, Fernandez ME, Markahm C, Bartholomew L. A taxonomy of behaviour change methods: an intervention mapping approach. Health Psychol Rev 2016;1 0:297-312.

Krouwel EM, Nicolai MP, van Steijn-van Tol AQ, Putter H, Osanto S, Pelger RC, Elzevier HW. Fertility preservation counselling in Dutch oncology practice: are nurses ready to assist physicians? Eur J Cancer Care 2017;26:el26|4.

Letourneau JM, Ebbel EE, Katz PP, Katz A, Ai WZ, Chien AJ, Melisko ME, Cedars MI, Rosen MP. Pretreatment fertility counseling and fertility preservation improve quality of life in reproductive age women with cancer. Cancer 2012; I 18:1710-1717.

Lombard M, Snyder-Duch J, Bracken C. Content analysis in mass communication: assessment and reporting of intercoder reliability. Human Communication Research 2002;28:587-604.

Louwe LA, Stiggelbout AM, Overbeek A, Hilders CG, van den Berg $\mathrm{MH}$, Wendel E, van Dulmen-den Broeder E, ter Kuile MM. Factors associated with frequency of discussion of or referral for counselling about fertility issues in female cancer patients. Eur J Cancer Care 2018;27:el2602.
Mersereau JE, Goodman LR, Deal AM, Gorman JAAR, Whitcomb BW, Su HI. To preserve or not to preserve: how difficult is the decision about fertility preservation? Cancer 20 I 3; I I 9:4044-4050.

NICE (National Institute for Health and Clinical Excellence Guidance). Fertility: Assessment and Treatment for People with Fertility Problems. 2013. https://www.nice.org.uk/guidance/cg I56. 22 October 2018, date last accessed.

Niemasik EE, Letourneau J, Dohan D, Katz A, Melisko M, Rugo H, Rosen M. Patient perceptions of reproductive health counseling at the time of cancer diagnosis: a qualitative study of female California cancer survivors. J Cancer Surviv 2012;6:324-332.

NVOG. Dutch Society of Obstetrics and Gynaecology. Fertility Preservation for Women with Cancer. 2016. https://www.oncoline.nl/ fertiliteitsbehoud-bij-vrouwen-met-kanker. 22 October 2018, date last accessed.

Oktay K, Harvey BE, Partridge AH, Quinn GP, Reinecke J, Taylor HS, Wallace WH, Wang ET, Loren AW. Fertility preservation in patients with cancer: ASCO clinical practice guideline update. J Clin Oncol 2018; | 4:38I-385.

Peddie VL, Porter MA, Barbour R, Culligan D, MacDonald G, King D, Horn J, Bhattacharya S. Factors affecting decision making about fertility preservation after cancer diagnosis: a qualitative study. BJOG 2012; I 1 9: 1049-1057.

Quinn GP, Vadaparampil ST, Gwede CK, Miree C, King LM, Clayton HB, Wilson C, Munster P. Discussion of fertility preservation with newly diagnosed patients: oncologists' views. J Cancer Surviv 2007; I: I46-I55.

Quinn GP, Vadaparampil ST, Lee JH, Jacobsen PB, Bepler G, Lancaster J, Keefe DL, Albrecht TL. Physician referral for fertility preservation in oncology patients: a national study of practice behaviors. J Clin Oncol 2009;27:5952-5957.

Quinn GP, Vadaparampil ST, King L, Miree CA, Wilson C, Raj O, Watson J, Lopez A, Albrecht TL. Impact of physicians' personal discomfort and patient prognosis on discussion of fertility preservation with young cancer patients. Patient Educ Couns 2009;77:338-343.

Rashedi AS, de Roo SF, Beerendonk CC, Woodruff TK et al. Survey of fertility preservation options available to patients with cancer around the globe. J Glob Oncol 2018;4:1-16.

Srikanthan A, Amir E, Warner E. Does a dedicated program for young breast cancer patients affect the likelihood of fertility preservation discussion and referral? Breast 2016;27:22-26.

Tschudin S, Bitzer J. Psychological aspects of fertility preservation in men and women affected by cancer and other life-threatening diseases. Hum Reprod Update 2009; I 5:587-597.

Wensing M, Bosch M, Grol R. Developing and selecting interventions for translating knowledge to action. CMA/ 20। 0; 1 82:85-88. 